\title{
EL CASO "PIERRE". COMENTARIOS AL TRATAMIENTO DE UN PACIENTE NARCISISTA
}

\author{
Fernando García Gil ${ }^{1}$ y Carlos Rodríguez Sutil ${ }^{2}$ \\ Madrid, España
}

Presentamos aquí un caso de un paciente con un trastorno narcisista de la personalidad. Debemos tomar el narcisismo, como el resto de los patrones de personalidad, como la respuesta del individuo a un contexto, como el resultado de una matriz relacional (Mitchell). El origen del narcisismo patológico está en unos cuidadores que desatendieron emocionalmente al niño, víctima del aislamiento, y que favorecieron y compartieron las fantasías narcisistas del mismo, confundidas con las suyas propias. La desregulación del narcisismo se produce cuando han sido ignoradas las necesidades del niño, lo que provoca graves alteraciones en la autoestima o la creación de un escudo defensivo grandioso (Morrison). Nuestro paciente al principio no podía aceptar ninguna falla en sí mismo pensando que el terapeuta tampoco aceptaría las suyas. El reto como terapeutas es asumir la incapacidad que el paciente nos atribuye, la incompetencia que el paciente persigue, sin caer en el desastre o en el infierno más absoluto que en definitiva es lo que más teme. Aceptar los fallos que el paciente desplaza en el terapeuta constituye una sorpresa para el paciente, incluso fue una experiencia correctiva en el encuentro con él mismo.

Palabras clave: Narcisismo, duelo, transferencia, vergüenza

We present here a case of a patient with a narcissistic personality disorder. We must take narcissism, like the rest of the personality patterns, as the response of an individual to a context, as the result of a relational matrix (Mitchell). The origin of pathological narcissism is to be found in caregivers who emotionally neglected the child, victim of isolation, on the one hand, and who share and promote narcissistic fantasies of the child, confused with their own fantasies. Dysregulation of narcissism occurs when the child's needs have been ignored, causing severe disturbances in self-esteem or the creation of a great defensive shield (Morrison). At first, our patient could not accept any fault in himself, assuming that the therapist would not accept his faults either. The challenge as therapists is to assume the disability that the patient attributes to us, the incompetence that the patient pursues, without us falling into disaster or in the most absolute hell, which is ultimately what he fears the most. Accepting the faults that the patient displaces in the therapist is a surprise for the patient, it was even a corrective experience in the encounter with himself.

Key Words: Narcissism, grief, transference, shame

English Title: THE CASE "PIERRE". COMMENTS ON THE TREATMENT OF A NARCISSISTIC PATIENT

\section{Cita bibliográfica / Reference citation:}

García Gil, F. y Rodríguez Sutil, C. (2020). El Caso "Pierre". Comentarios al tratamiento de un paciente narcisista. Clínica e Investigación Relacional, 14 (2): 412-430. [ISSN 1988-2939]

[Recuperado de www.ceir.info ] DOI: 10.21110/19882939.2020.140209

\footnotetext{
${ }^{1}$ Licenciado en Psicología, miembro titular de la Asociación Española de Terapia Gestalt y de la Asociación Española de EMDR.

2 Doctor en Psicología, Psicoanalista Relacional, Instituto de Psicoterapia Relacional.
} 


\section{Introducción}

Presentamos a continuación la descripción y comentarios cobre el caso de un paciente con un tipo de personalidad predominantemente narcisista. El paciente fue atendido por uno de nosotros (FGG) y visto en supervisión por los dos a lo largo de varios años. El criterio que define este prototipo es la grandiosidad de la propia imagen y la falta de empatía hacia los demás. Considera a los otros como objetos útiles para los propios fines, pero carece de la tendencia al acting del agresivo: seduce más que agrede. Hipersensible a la evaluación negativa, ante la que puede reaccionar con rabia, vergüenza o humillación, pudiendo alcanzar un estado de gran tristeza, con riesgos de suicidio, que desde la psicopatología dinámica se ha venido denominando "herida narcisista" (Cf. Rodríguez Sutil, 2014).

Desde el primer momento, debemos tomar el narcisismo, como el resto de los patrones de personalidad, como la respuesta del individuo a un contexto, como el resultado de una matriz relacional, como diría Stephen Mitchell (1988, parte 4). Mitchell pone en el origen del narcisismo patológico a unos cuidadores que desatendieron emocionalmente al niño, víctima del aislamiento, por una parte, y que favorecieron y compartieron las fantasías narcisistas del mismo, confundidas con las suyas propias, sin ninguna capacidad para la crítica realista. Mitchell cita a Atwood y Stolorow, cuando comenta que desde la psicología del self no solo se ha señalado en el narcisismo la incapacidad de los padres para proporcionar la función de objeto del self al hijo, como el uso del niño como objeto del self por parte del progenitor.

Pensamos que puede ser de un interés especial la revisión de esta terapia por la relativa rareza de este tipo de pacientes en la consulta, sobre todo si nos referimos a pacientes "piel dura" o "piel gruesa". Algunos tipos de trastornos, como la personalidad narcisista o la antisocial, y muchos trastornos psicóticos, se acompañan de una escasa o nula conciencia de que exista ningún trastorno, por muy inadaptado que se encuentre el sujeto. Joan Coderch (2006) alude a la diferenciación entre personalidades narcisistas perversas y personalidades narcisistas infantiles, otra manera de distinguir el narcisismo de "piel gruesa" frente al de "piel fina" - "Thick skin/thin skin narcissism" según la terminología de Herbert Rosenfeld (1987). El narcisista de piel dura es un sujeto con estructura de personalidad narcisista, mientras que el narcisismo de piel blanda es un patrón de comportamiento que puede aparecer de forma más ostensible en los trastornos graves de la personalidad. La vergüenza es el sentimiento intenso que viven las personalidades narcisistas, que llega a ser abrumador en las de piel dura, cuando se produce. A estos últimos sujetos sería aplicable el interesante desarrollo de Rubén y Raquel Zukerfeld (Zukerfeld y Zonis, 2011) sobre la subjetividad aquileica - de Aquiles - condición subjetiva que supone una vulnerabilidad equilibrada o 
compensada por la adherencia a ideales culturales dominantes, como una armadura que cubre o defiende, pero no permite transformación alguna. Aquiles es un modelo de héroe clásico, capaz de las mayores crueldades por una causa idealizada, la gloria, el honor, el reconocimiento.

Kohut (1966, 1971) consideraba que el narcisismo tiene una línea de desarrollo independiente de la libido de objeto. En opinión de Morrison (2008), la desregulación del narcisismo se produce cuando han sido ignoradas las necesidades del niño, lo que provoca graves alteraciones en la autoestima o la creación de un escudo defensivo grandioso. Las expresiones del narcisismo herido quedan guardadas en el interior. Las heridas y detenciones en el desarrollo pueden ser provocadas también por demandas excesivas. Subraya la relación íntima que guardan el narcisismo y el sentimiento de vergüenza, relación a la que el autor ha denominado "dialéctica del narcisismo". El narcisismo, ya sea originario o posterior, es una retracción del afecto positivo hacia sí mismo, una vez que existe un "sí mismo", un self, mínimamente constituido. Como bien dice Morrison (2008), cuanto mayor es la discrepancia entre el self ideal y el self real, mayor es la vulnerabilidad ante la herida narcisista y, también, la susceptibilidad ante la vergüenza. La experiencia afectiva interna comenta - que representa al narcisismo, y que en algún grado está presente en todos nosotros, es un deseo de ser especial. Especial para otro concreto, significativo, alguien a quien hemos dotado de significatividad y poder. En su versión más patológica, ese deseo de ser especial a los ojos del otro idealizado lleva al anhelo por ser absolutamente único y, en definitiva, por ser el único objeto de importancia para él o ella.

La vergüenza se declara cuando uno está totalmente expuesto y consciente de estar siendo observado, en una palabra, es auto-consciente. Uno está visible y no está preparado para estarlo, por ejemplo, semidesnudo, "con el culo al aire" (Erikson, 1959). Dan ganas de esconder la cabeza o de que te trague la tierra. En algunas culturas tradicionales se utiliza la vergüenza como método educativo y esto a Erikson le parece menos destructivo que la culpa utilizada de forma predominante en Occidente. Algo con lo que no estamos de acuerdo, al menos no siempre, tras conocer el papel que el sentimiento de vergüenza desempeña en la disociación, como bien ha mostrado Bromberg (2011). La vergüenza explota un sentimiento creciente de ser pequeño que, paradójicamente, se desarrolla cuando el niño es capaz de mantenerse de pie, adquiere autonomía motórica y toma conciencia de las medidas relativas de tamaño y poder, y que se suele repetir en la adolescencia con cierta intensidad.

Se podría argumentar que no ganamos mucho si pasamos de una concepción del ser humano culpable por sus deseos, el neurótico, a un ser humano culpable por su propia identidad y circunstancias. Pero este sujeto (esquizoide-límite) no es tanto culpable por sí mismo como 
por haber sido rechazado por su entorno familiar, por no haber recibido el adecuado reconocimiento. El ser humano no nace individualizado en un mundo con el que comienza a relacionarse, sino que la diferencia entre el interior y el exterior es un complejo proceso que se logra en el desarrollo. Freud (La Negación, 1925) está en lo cierto cuando sugiere que el pensamiento abstracto (el juicio) cuando aparece termina asegurando esa diferenciación de dos espacios: consciente e inconsciente. Una vez separados se puede hablar de "conflicto intrapsíquico", como es corriente en psicoanálisis. Sin embargo, esa noción sólo comprensible desde una concepción occidental del hombre, aquella que hace de la persona un sistema cerrado y autosuficiente, con el sentimiento de culpabilidad como motor del funcionamiento psíquico interpersonal. La vergüenza, en cambio, es uno de los principales afectos del self (al avergonzarse de sí mismo uno se avergüenza de lo que siente que es), y la culpa es uno de los principales afectos del conflicto pulsional clásico (culpa por los deseos sexuales infantiles). Dicho de otra manera, uno se siente culpable de lo que hace y se avergüenza de lo que es. Estos patrones de reacción han sido transmitidos al niño desde muy temprano, en contextos pragmáticos interpersonales.

\section{VIÑETA}

Inicio

Pierre es un hombre de 31 años, ciudadano francés. Nació en un pueblito cercano a París. Actualmente lleva en terapia cerca de cuatro años. Ingeniero de sistemas, estudios que finalizó en una universidad parisiense. Actualmente reside y trabaja en Madrid. En la primera sesión cuenta que lleva cuatro años en Madrid y que para él ha sido positivo cambiar de ciudad, ante vivía en la capital francesa. Actualmente está comenzando una relación con una chica española. Dice estar enamorado y le han surgido cosas del pasado.

Cuando terminaba sus estudios comenzó una terapia, de corte analítico, que duró aproximadamente un año. El motivo fue un ataque de pánico al terminar el último examen. "no lo vivía como ir a terapia, era una amistad, el analista era un señor mayor, era un amigo, pero no volvió el ataque de pánico". Este comentario puede tomarse como una reacción contraria a toda forma de dependencia o, dicho de otra forma, a reconocer alguien con un estatus superior.

A continuación, habla de Silvia su pareja actual: "Ella tiene 26 años, tuvo una vida dura, llena de heridas y relaciones con personas más mayores que ella. La relación entre nosotros es apasionada y muchas peleas. Yo a ella la siento en el estómago. Llevamos siete meses juntos y se está perdiendo intensidad, pero estoy feliz de estar con ella, la quiero. En otras 
relaciones pasadas no he dado nada". Reconoce, por tanto, su "incapacidad para dar", al menos en las relaciones pasadas, característica que Fairbairn (1940) atribuía acertadamente a las personalidades de tipo esquizoide.

En cuanto a sus padres comenta: "mis padres han vivido juntos cerca de 25 años y se separaron cuando yo tenía 23, mi hermana Marie tiene dos años más que yo (Su hermana siempre ha sido exitosa en los estudios, algo muy valorado por la familia, en cambio Pierre siempre tuvo dificultades académicas. Pierre siempre tuvo celos de su hermana). Mis padres se hacían daño y mi madre siempre fue infeliz. Mi madre ama de casa, pero nunca trabajó y mi padre ha sido abogado en una empresa. Mi madre se marchó con un conocido de mi padre y desde entonces no se hablan, creo que mi padre no lo superó. Mi padre es cerrado, siempre viendo la tele, pero es inaccesible y muy inteligente, nunca ha tenido cojones. Mi madre no quiere que tenga el camino de mi padre, mi padre es un pesado y ahora tiene una pareja más joven que él, una mujer super operada. Silvia me dice que no he perdonado a mi madre. Quizás me ayude darle una vuelta a estas cosas". Pierre describe a su madre como alguien infeliz e insatisfecha en la relación con su padre, esperando que cambie de actitud y se convierta en alguien trabajador, activo y familiar. Parece indicarnos que Pierre convivió con la representación de un padre frágil, cobarde, una imagen de un progenitor devaluado e impotente que no sabe enfrentarse a las vicisitudes y dificultades de la vida.

Comenta haber tenido tres relaciones de pareja en su pasado. Marie fue su primera relación. Empezó con 18 años y estuvieron varios años juntos; una relación que le proporcionó protección, como si de una madre se tratara. Habla del miedo que sentía en las primeras relaciones sexuales, el temor a hacerlo mal; se sentía acomplejado, también por verse desnudo frente a alguien: "igual se rien cuando estoy desnudo". Pierre ofrece una sonrisa aparente y arrogante, capaz de ocultar sus propias vergüenzas en relación con los demás. La vergüenza sería un sentimiento común al narcisismo de piel dura y de piel fina, pero más infrecuente, intenso y destructivo en el primero.

Tras finalizar sus estudios conoció a Inés, una joven española de 23 años que estudiaba en París. "Me hizo sentir un Dios en la cama, yo me fijo en el placer de ella, le daba placer, ella odiaba a los hombres, sufrió abusos". Se trasladan juntos a Barcelona, donde conviven varios años. En este periodo Inés se aísla en casa, se va deprimiendo, se niega a mantener relaciones sexuales con él. Pierre se venga y comienza a disfrutar la noche, el alcohol y otras mujeres: "Yo tenía ganas de vivir y sexo y esto me ha salvado. No me sentía culpable de poner los cuernos. Quiero estar aquí, los domingos son tristes en todo el mundo menos aquí".

Antes de romper la relación con Inés conoce a Dolores, una mujer dos años menor que él: "En esa época me acostaba con otras mujeres". Dolores se enamora, pero él le hace saber 
que no la ama: "Dolores era mi objeto, lo que yo diga lo hace. Ella era mi alfombra, y no me sentía culpable, era mi esclavita, pero ha sido mi apoyo durante dos años". También por esta época mantiene relaciones sexuales con una mujer de 50 años: "Un sueño tener a la mujer mayor, además me parecía normal estar con diferentes mujeres, ahora no". El otro ocupa un lugar secundario, es usado sin experimentar culpa.

En este momento ocurre un suceso que paraliza momentáneamente a Pierre. Un primo muere repentinamente. Pierre acude impresionado al entierro: "Agradezco a la vida, he sabido lo que es vivir". En este momento de su vida abandona a Inés. Habla de morir en paz. Aquí Pierre habla de sus motivaciones en la terapia: "vivir sin miedo a tener cáncer" o padecer una enfermedad", "miedo a perder a Silvia" (su pareja actual) y al final comenta "ella quería que yo viniera a terapia".

Tras ocho meses de relación, Pierre y Silvia deciden convivir en un piso alquiler. Esta situación durará año y medio, aproximadamente. En todo este tiempo se suceden las luchas de poder por tener el control en la pareja: "Es una lucha de poder, no me interesa, pero lo voy buscando, ocurre la lucha de poder, no quiero pelear, pero que no me pisen, aunque se lo he puesto difícil al principio. Desde las primeras citas con ella hemos peleado. Yo le tomo el pelo a ella". Pierre comenta que su adolescencia fue una lucha contra sus padres "un desastre de adolescente"-según dice, mantuvo una conducta rebelde para que se hablara de él: "Tomaba el pelo a los profesores, a la gente, los profesores me odiaban. Cambié cuatro veces de colegio, estudiaba poco, mi madre decía que soy odioso, pero la que siempre estuvo ahí fue mi madre. Mi madre no le veía solución, en cambio mi padre no se enfadaba nunca ni me defendía nunca". Tiene conquistado el vínculo con la madre, pero es una relación que suponemos distante, poco afectiva y un tanto desde el desengaño y la agresividad.

Silvia es una mujer nacida en Argentina de emigrantes españoles, que viene a vivir a España con ocho años. Sus padres se separaron cuando ella nació. Pierre la considera fuerte, bella y seductora, muy activa sexualmente, acostumbrada a diferentes prácticas sexuales como intercambios de parejas, tríos etc. Aunque ni él ni ella han propuesto estas prácticas, Silvia sí tuvo este tipo de experiencias. Pierre señala que nunca le propondría a Silvia prácticas sexuales fuera de la pareja, pero también añade: "aunque sueño y me excita imaginármela con otros hombres". Pierre es consciente de que Silvia, con su estilo provocador moviliza la mirada masculina y es algo que le excita y a la vez envidia. Se refiere a Silvia en estos términos: "es una polla sensible. La venero como a un diosa en la cama, tengo sensaciones como nunca, me dice que sus orgasmos son como nunca los había sentido ella". En este sentido realza su imagen grandiosa, omnipotente, capaz de controlar y producir placer en 
una Diosa. "mi padre en cambio es un perdedor, envidioso, es poco emprendedor, aunque le tengo en un pedestal y añade que para ser un ganador hay que ser un poco hijoputa".

Alardea de tener la capacidad para provocar explosiones agresivas en los otros, llevándolos y acosándolos hasta el límite: "En una ocasión le dije a Silvia que follaba como un demonio y explotó". Justifica su reacción con lo que parece un uso de la renegación (Verleugnung, Freud, 1927): "a mí no me ofendería". También se enorgullece de haber provocado explosiones de ira en su madre y puntualmente en su hermana: "Mi hermana me odia, yo quería que mi hermana se diera cuenta que las cosas son como yo digo, por eso la hice explotar. Mi hermana ha sido la hija modelo". "Mi padre es un evitador de conflictos, sólo explotó dos veces y me destrozó algunos juguetes, yo gritaban que me están violando para que parara". Desde pequeño debió de mostrarse con gran habilidad a la hora de buscar los puntos débiles del otro, hacía explotar a los demás sin ningún tipo de consecuencias.

\section{Crisis}

Tras cuatro meses de análisis se produce, como probablemente era de esperar, una transferencia masiva, negativa y sádica. La sensación que produce al terapeuta (FGG) es de falta de vinculación, como si se hablase a sí mismo, defendiéndose de los escasos señalamientos, mostrando su actitud arrogante y violenta en el vínculo. En este momento el terapeuta siente que necesita administrarse la tensión agresiva en dosis más pequeñas y, tras comentarlo en supervisión, introduce un cambio en el encuadre: la sesión de 50 minutos habituales cambia por dos sesiones semanales de menor duración - de unos 40 minutos pero que permiten una gestión más intensiva de la crisis, en las que se van señalando las diferentes defensas agresivas:

-Desconfianza en el vínculo: "no sé si me fio"

-Agresiones: "tú eres un personaje", y otras expresiones en tono despectivo.

-Actitud arrogante desde el sí mismo grandioso: "yo decidiré al final si esta terapia me vale o no me vale".

-Dice tener la sensación de ser atacado por el analista. En ocasiones muestra indiferencia por la terapia, en otras ocasiones hace interrupciones donde se activa su rabia. Se alternan transferencialmente las figuras de omnipotencia-desvalorización y desprecio.

Señalando estos mecanismos, con la mayor calma posible por parte del terapeuta, pasan más de seis meses. Tras cerca de un año de análisis habla de su vivencia de la envidia: "Nadie me va a convencer de nada, todo el mundo es envidioso, creo que sé reconocer cuándo mi 
envidia es insana, veo el que la tiene más larga o el que es más listo que yo". También reconoce la envidia y el odio al sexo opuesto: "las chicas tienen el poder, la minifalda, me he vengado, me he aprovechado de ellas". Después intenta una reparación ineficaz: "Dolores me daba pena, la he cagado".

\section{Desarrollo de la terapia}

En una ocasión le comenta a Silvia que ha estado con unas 15 o 20 mujeres. (Una actitud exhibicionista, un despliegue triunfalista y omnipotente de superioridad que enmascara envidia).

T-¿Y qué te dijo ella?

P- Me dijo que qué tierno...(irónicamente)

T- ¿Por qué se lo dijiste?

P-¿Y por qué no? -Devuelve la pregunta defensivamente.

T-¿Tú crees que ellas lo hacen también? (Para explorar si piensa que las mujeres también utilizan a los hombres. También para valorar la grandiosidad y el odio hacia las mujeres).

P-Sí usar y tirar, ellas han hecho lo mismo conmigo (se justifica con una posición de víctima) y las he hecho sufrir. Estuve con una mujer casada en una ocasión. Yo era el jovencito y ella me usó a mí como yo has he usado a ellas.

En otra sesión surgen escenas que pretenden provocar celos y la explosión de Silvia:

P-Me ha pegado dos puñetazos y lo hizo delante de la gente por celos. Ella había bebido, estaba fuera de control, decía que quería desnudarse. Está loca, no me respeta. (Su ideal de respeto es el de un hombre al que solo con mirarle se le respeta, se entiende que se le admira también). Para ella los hombres no tenemos alma y me planteo si merece la pena seguir o no, pero cuando estoy solo me siento inseguro.

P- ¿Qué ocurrió para que se comportara de esa forma?

P-Me dejé el ordenador abierto, ella miró y vio a Dolores.

Nos queda la duda de si se dejó el ordenador abierto por accidente o, más probable, intentaba provocar celos en ella para demostrar su dominio.

En una sesión posterior describe cómo la relación con Silvia está dando sus últimos coletazos: 
P- Ella no me soporta, tendré mi parte, ella es violenta

T- ¿Te has planteado qué te aporta una persona violenta?

P-No lo sé.

T-Hasta ahora a ella no la has destruido...[silencio]. (Ya hablamos sobre ello en otros momentos, sobre su destructividad).

P-Qué cabrón, estarás disfrutando...[silencio]. (El terapeuta percibe la vergüenza y el odio hacia él).

P-Sólo te observo (sonríe con gesto placentero).

T- Obsérvate tú.

T-Parece que me ves disfrutar haciéndote daño, pero noto que sonríes quizás como disfrutando, como si hubiera algo en ti que siente placer anulando las ideas que intento aportar. (Señalamiento de la proyección).

Parece no ser capaz de ver lo positivo de Silvia, más allá de poseer a un Diosa, a "mi tesoro" como él suele referirse a ella, como ideal envidiado.

$\mathrm{P}$-A veces tengo la sensación de que el otro es igual que yo, no me escucha

T-Tengo la impresión de que me escuchas sólo si hablamos de tu ser maravilloso y estupendo, pero difícil si no encaja (confrontación).

En sesiones posteriores ve indicios de que Silvia se puede marchar, ha hecho un par de amagos ya: "Ella me cae mal, Silvia me limita, ya me callo y no le contesto. Intento no engancharme a sus enfados. Ya no puedo tomarle el pelo. Silvia ha dejado a todos los tíos con los que ha estado".

T- ¿Cómo vives eso?

P-Creo que cualquier mujer no va a ser como ella. Lo que pasa es que cuando está bien física y sexualmente.... es como si fuéramos uno y no sé cómo salir de ahí.

En otra sesión:

P-Me veo más tranquilo, a lo mejor Silvia no es para mí. He ganado en salud. Pienso en no tenerla y estoy solo. Toda mi vida la he enfocado a ella. Yo no la voy a dejar, vivo en la ilusión. Mi madre me dice que perdió veinticinco años de su vida esperando que mi padre cambiara.

Cuenta un sueño: 
Encuentro un trabajo en Rusia, en el avión hay otra chica. Yo voy con Silvia y yo estaba abrazado a esa otra chica. Yo quería a Silvia pero tengo sensaciones con la otra chica. Eso es nuevo para mí. Yo no sé ruso y la chica me habla en ruso y Silvia se vuelve a Barcelona. Luego nos volvemos a ver Silvia y yo y ella toma conciencia de que hay otra persona en mi vida y yo triste. Que se ha acabado la magia. Yo le digo que quiero estar con ella, aunque peleemos. Siento angustia.

Muy a menudo, el que el paciente cuente un sueño implica una buena marcha de la terapia, una facilidad para confiarse en el otro. Este sueño, aparte de ser un relato de la situación de pareja que está viviendo y de la solución, en parte ideal, que se propone - una pareja sustitutoria - habla por primera vez de la angustia. Este temor a la pérdida del otro se debe considerar un elemento de evolución, prometedor, en el tratamiento. Hasta ahora sólo había aparecido el miedo a no tener un buen rendimiento sexual con sus primeras parejas, es decir, una amenaza a su imagen.

En otras ocasiones cuenta que no puede dejarla, que Silvia es, como decíamos, "su tesoro, su anillo"-tomado de la película El Señor de los Anillos. Habla de "esa sensación de poseer algo maravilloso, un objeto maravilloso". Pero se imagina que Silvia se puede marchar.

En otra sesión describe lo que siente en su interior:

Bob: Es un espíritu como la película de Laura Palmer de la serie Twin Peaks. He tenido miedo hasta los veintiséis años, he dormido con la luz encendida. Un espíritu no lo puedo controlar. Sueño con malas presencias que me dan miedo. Bob parece representar la parte más persecutoria. En la serie Twin Peaks Bob es un fantasma, un espíritu que se alimenta del dolor y del sufrimiento ajeno. Es un ser de otra dimensión que posee a los seres humanos para posteriormente asesinar y cometer actos y violaciones.

Pérdidas: Miedo a perder. El impacto de la muerte de su abuela (murió cuando era niño). Recuerda cuando echaron la tierra encima del ataúd. "Nunca lloré por mi abuela. Desde los catorce tengo miedo a que le pasa algo a mis padres".

Cáncer: "No puedo olvidarme de mi primo (murió de cáncer). Es real, es una piedra negra, la fragilidad. Miedo a la enfermedad. El padre de mi madre se murió de cáncer y un primo joven también". Comenta que tiene la angustia ante la muerte desde muy pequeño y "el miedo que veía reflejado en mis padres". "Mi madre siempre me habla de gente que se ha muerto". El objeto persecutorio, es decir, el cáncer y la enfermedad en el cuerpo, son aspectos que Pierre no puede controlar.

Pero muestra el otro lado de lo que existe dentro de él: "La vida ideal, follar para contarlo. Como vacío, porque hay algo que no funciona (ese vacío lo protege Silvia) No sé lo que 
quiero. Bueno quiero ser un crack, especial y único". (Sigue asociando) "A los dieciséis años quería ir a un monasterio budista, quería ser monje y no me dejaron mis padres. Y si Silvia quiere irse que se vaya. Hay esperanza. Es una hija de puta, le he dedicado todo. Me siento culpable por lo que hice con Dolores". Tras confrontarle los sentimientos de culpa señala que en realidad a Dolores la tiene en recámara, como suplente. Dice que es agresivo y no se siente culpable.

Tras varias sesiones, Silvia le ha comentado que quiere dejar la relación. Sospecha que Pierre es mala persona y la envidia constantemente. Tras varias escenas de maletas en puerta, Silvia decide marcharse de la casa. Durante este tiempo, Pierre no parece muy deprimido. Se organiza actividades, hace Yoga, va al gimnasio, boxeo, sale los fines de semana, alguna relación esporádica, algunos viajes, practica el surf, conoce otros aventureros, idealiza alguno por su temeridad y la seguridad en sí mismo. Tiene varios amigos, pero fuera de España. Todos franceses. Un amigo que vive en Suiza y que fue un gran apoyo para mantener continuidad en la carrera universitaria y llegar hasta el final.

Pierre trabaja como comercial en una empresa que fabrica piezas de avión para una conocida multinacional. Antes trabajó durante un año en otra multinacional en España, pero no le renovaron el contrato. Según dice es muy difícil que renueven a los que llevan poco tiempo. Después intentó volver a trabajar en esta primera multinacional enviando currículos, pero nunca le llamaron para entrevistas. Ha idealizado la multinacional durante mucho tiempo.

En la empresa donde trabaja no está contento. Las relaciones con los compañeros no son muy buenas. Entra seduciendo y bromeando con todos, pero posteriormente siente que se ríen de él y le toman el pelo. En su trabajo debe reportar directamente con el director, con el que tiene muy buena relación. Se trata de un director que lleva tiempo en la empresa, parece quemado por los años y Pierre se siente identificado con él. Tiene que trabajar en equipo, pero los compañeros le meten prisa y se siente exigido y presionado. Siente que su labor no es valorada y se va aislando de los compañeros. Se da cuenta de que tiene dificultades para colaborar con otros y su tendencia a imponer sus argumentos.

Durante este tiempo comienza a idealizar otra empresa, TERAX. No se dedica a la aeronáutica sino a la distribución de productos alimentarios. Llegó a estar cuatro veces como candidato final a los puestos que la empresa solicitaba, pero siempre quedó en puertas. "No entiendo yo que tengo yo para que no me llamen". Sospechamos que los responsables de selección perciben una personalidad poco adaptativa para el trabajo en equipo. Se trabaja en sesión la forma que tiene de presentarse a las entrevistas. Se le propone que mentalice que sensación puede causar en el otro (Fonagy, 1991). Poco a poco se siente menos rechazado y deprimido en cada descarte y va asumiendo que puede tardar tiempo, pero 
seguirá en su "empeño". Un año y pico por fin consiguió entrar en TERAX. Fue constante en su empeño pese a las cuatro frustraciones.

Más o menos ocho meses después vuelve a reencontrarse con Silvia - en realidad, nunca dejaron de tener contacto - y viven juntos otra vez. La convivencia duró algo más de dieciocho meses. Además, deciden hacer terapia de pareja para intentarlo de nuevo.

\section{Elaboración de la dinámica familiar}

Durante este tiempo intenta comprender lo que ha pasado en los vínculos familiares. Pierre se crió con su padre, madre y hermana, unos años mayor que él. La relación con los tres es distante, pero peor con su hermana. Los padres se separaron cuando Pierre estaba en la Universidad. La madre se fue con un amigo del padre, cansada de la actitud pasiva del padre, después de 30 años. El padre era un abogado fracasado. Lo describe como pasivo, lejano, incompetente en su trabajo, dependiente e inteligente. La madre impulsiva, agresiva, todo el mundo le debe comprensión, autoritaria, quiere imponer su criterio, sin límites, agresiva con él, que pelea con todo el mundo "y chocamos mucho". Ahora Pierre le dice a la madre "¿Qué aporta esto ahora a nuestra relación?", en un sentido conciliador. No obstante, le agradece dos cosas. Que le comprara un aparato para nivelar sus dientes en la infancia, porque se sentía ridículo, y que peleara para ingresarlo en un colegio privado para poder terminar secundaria y bachiller, por la menor exigencia académica de la institución. En estos y otros asuntos se siente abandonado por el padre. Siendo pequeño le pegaban sus primos mayores y su padre nunca le protegió, como sí hacían los otros padres.

En casa había problemas económicos. El padre apenas tomaba clientes porque, según Pierre, le daba miedo enfrentarse a los juicios y a los problemas. "Y sobrevivíamos por una herencia que mi padre había recibido de sus padres, pero no nos daba para ir de vacaciones, y yo sentía envidia de otros niños que sí iban. Me doy cuenta ahora de que mi padre no iba al trabajo como yo no iba a las clases". Dice que no se siente orgulloso de su padre.

A lo largo de la terapia comenta estar viviendo un proceso de aceptación del padre:

P- Es que siempre era mi padre la víctima, el que parecía el enfermo de la familia, pero hay un cambio de paradigma y ese proceso ya empezó.

T- ¿Cuál?

P- Que el malo era él en la familia, mi padre, pero yo llegué a pensar que el malo era yo por mi comportamiento rebelde y que yo era el causante de las depresiones de mi madre. 
Entonces cuando Silvia estaba triste yo pensaba que era por mi culpa, pero yo ahora no pienso eso, yo intento calmarla.

Recuerda que su madre tenía idealizado a su hermano mayor. Un hombre dominante y machista que él también tenía idealizado e incluido en su yo grandioso. Fuimos elaborando esta parte en terapia. Más adelante siendo consciente de este ideal de hombre macho dominante y la sumisión a este ideal materno, se rebela contra su tío y en una ocasión le manda callar:

Tío- ¿Qué tal con esa, como vas, habrás follado mucho no? (En ese momento se sintió ofendido).

P-Te pido que respetes a mi pareja, ella es mi novia y te pido que hables con respeto de ella, porfavor.

También puso límites a comentarios que su padre hacía despreciando a las mujeres.

Comenzaron además terapia de pareja con una terapeuta de familia que el terapeuta (FGG) le había recomendado. Una terapeuta con experiencia con trastornos de personalidad. La terapia duró seis o siete meses porque esta terapeuta enfermó y falleció poco tiempo después. Durante esta terapia surge la desconfianza con la terapeuta y la transferencia negativa: "El truco es callarse, hay que tener cuidado con ella. Te hace preguntas y sabe lo que vas a contestar. Da igual lo que digas, le da un sentido a mis palabras que ella quiere y no es eso lo que yo quiero decir. En la siguiente sesión le dije lo que hablamos, que ella me echó para abajo y me sentí desvalorizado y se lo dije. Me pidió perdón, os he liado nos dijo. Mejor así, no callarme".

En esa sesión hablamos de su parte provocadora, de su desafío y provocación continua a los demás, el desprecio a los demás. "Puedo entender que ahora también se me tome así. Odio y desprecio todavía, queda esa dualidad. Se ha activado esa dualidad con la terapeuta, la lucha de poder y la dificultad con la frustración. Pero yo he rebajado la agresión, no necesito someter a la gente." En otro momento comenta: "Llevamos tres meses con la terapeuta de pareja, no es irresoluble el problema que tenemos, la lucha de poder. Volvemos atrás los dos y peleamos. Dice la terapeuta que estamos madurando, no es grave, digo. Nos damos cuenta de que es una lucha de poder y no es poco. Ella cree que no soy tan hombre para satisfacerla. Yo no me atrevería a ir con otra para poner en riesgo la pareja".

En otras sesiones reflexionamos sobre el placer que le daba someter a los demás: "Con la segunda pareja que tuve yo siempre he tenido eso, no podía parar de aprovecharme de ella. Ella era la alfombra sobre la que yo pisaba, me daba cuenta y seguía haciéndolo y no tenía parte de culpa. Le dije que se olvidara de mí, yo la trataba mal. Ellas hacían de madres 
conmigo, las usaba. Tienen ese punto de madres con el hombre necesitado y yo me pongo de hijo. Pero Silvia de madre no tiene nada".

P- Hubo una etapa que me daba vergüenza con las chicas, pero yo siempre el protagonista, nunca le he dado protagonismo al otro.

T- Podría ser tu tendencia a destruir las cosas que recibes, las cosas buenas. (Nos referimos a la envidia en el sentido kleiniano).

P- He destruido tanto, mi familia me soportaba y ahora he recuperado la relación con ellos. Con mi hermana ninguna relación, la he rebajado, otra víctima de mi protagonismo, pero ahora la valoro.

Después del intento de terapia de pareja, la relación con Silvia se va deteriorando más. Va viendo que tiene una parte de demonio interior (Bob) pero que, según él, ya no le domina tanto:

P- No siento que hay ese sadismo (...) Yo tenía un gato y le pegaba. Ver cómo el otro sufre me ha dado placer, me vengo arriba.

T- ¿Cómo lo ves ahora?

P- Me da vergüenza, no me gusta. Pero no identifico a veces cuando la gente se pasa conmigo en el trabajo. Y luego pienso que me están sometiendo. A veces estoy molesto y me sonrío y otras, sobrerreacciono.

En la transferencia, el terapeuta no percibe en estos momentos de la terapia su sadismo. Sí se produjo un punto burlón, desvalorizador, en los primeros meses de terapia, o en momentos en que se siente inferior, pero en general no lo vive como una amenaza para él. Se representan, más bien, las figuras de un padre bueno comprensivo y un niño escuchado, cuidado e importante (padre ideal y niño cuidado). Esta forma de transferencia positiva nos recuerda la caracterización que hace Kernberg $(1994,1996)$ del síndrome de narcisismo maligno, en sujetos que conservan la capacidad para la lealtad y la preocupación por los demás, con cierta capacidad para sentir culpa y empatía, que este paciente va logrando poco a poco, pero que pueden mantener conductas antisociales (pasivo-parasitarias), pueden desenvolverse como auténticos agresivos que han alcanzado el nivel de las operaciones formales, o como casos intermedios entre los prototipos narcisista y agresivo.

El padre enferma de Alzheimer y es ingresado en la UCl, también le detectan "un bulto" en la vejiga. Él vuelve a Paris durante el ingreso. Le encontraron desmayado en su casa. En el hospital Pierre le tuvo que peinar, cuidar, lavar los dientes etc. "Sé que le he tranquilizado, es la primera vez que hago algo por él. Siento que él ha tenido que contar conmigo y me ha 
hecho sentir importante. También he soñado contigo. En el sueño tenía miedo a que me descuartizaran y llegabas tú, que eras el jefe, y me tranquilicé".

Respecto a la relación con Silvia, se posiciona de manera autoritaria con ella. Además, Pierre le ha pagado a ella un máster de terapia: "como yo pienso que se deberían hacer las cosas". Ella le reprocha que cada vez está más lejos y no comparten actividades. Silvia baila muy bien y Pierre no soporta que ella siempre sea el centro de la pista: "De fondo tengo miedo porque no me siento a su altura, no doy la talla. Bob el fantasma me dice que tenga sexo con otras, ganas de salir corriendo. Pienso que Silvia nunca está contenta y la vida de los otros siempre es mejor. Yo me pongo odioso, pero no lo hago con mala intención, pero me pongo odioso". Nota la envidia hacia Silvia, su coraje, su nivel de yoga, su capacidad para seducir y ser el centro. "La envidio" dice con gran intensidad.

Silvia también empieza a poner distancia en la relación, no quiere tener relaciones sexuales con él, dice que no puede, empieza a evitarlo. "Yo sueño con la Silvia prohibida, con la que ha hecho orgías y tríos. La Silvia que veo es la niña amorosa y no me despierta atracción sexual. Yo siento que con las mujeres he sido como el hijo a cuidar y ahora me siento como el padre con ella que nunca la satisface. Creo que el deseo está en otro lado, si por ejemplo la viera a Silvia con otro me excitaría". Hay aspectos de Silvia que le dan mucha rabia: "Me ignora, está todo el día con el móvil, me dice 'déjame tranquila tengo que trabajar', se siente pequeña con los demás. Y ella mira a otros y yo me siento pequeño, desvalorizado. Yo me pongo odioso y no soy capaz de pararme a tiempo y hago daño" (...) "Yo sé que la quiero, pero a veces quiero salir de la relación. Sé que no es fácil estar conmigo, yo me siento desvalorizado y mi primer impulso es ponerme por encima, quizás en mi interior me siento inferior, me pongo por encima y eso me da calma. Ella me dice que soy agresivo y ya y me siento una mierda. $Y$ yo ya no soporto sus despistes y su manera de hacerse desear a los demás". En realidad, parece que siente el miedo a ser abandonado por ella, pero también podemos observar mayor capacidad de reflexión en su discurso.

En otra sesión añade que Silvia es caótica, impulsiva, agresiva, desordenada y piensa que no podría formar una familia con ella. Que tener hijos con ella sería caótico. "Estoy harto de la lucha de poder con ella, por ejemplo, el espacio ella lo ocupa todo y yo estoy durmiendo en un rincón, apenas tengo sitio. Ella todo lo invade. He salido con la gente de la empresa me llamó veinte veces y al llegar parecía como loca. ¿Con cuantas rubias te has acostado hoy?". Días más tarde Pierre cogió sus cosas y se marchó de la vivienda común. Seis meses después de la ruptura sigue enganchado a la representación ideal de Silvia. Ahora se queja de inhibición del deseo sexual cuando conoce a otras mujeres. Añade que la primera vez que Silvia se marchó, él siempre tuvo la esperanza de que volverían a estar juntos. "Esta vez es 
diferente, no tengo deseo sexual". Esta falta de deseo es también un detalle importante en la evolución del caso, que hablaría de cierta reacción de tipo depresivo no propiamente narcisista.

\section{CONCLUSIONES}

El proceso terapéutico se ha dividido en dos momentos diferentes. Un momento inicial donde los primeros compases terapéuticos se han definido por la singular apuesta transferencial del paciente. Una idealización superficial del terapeuta que pasó inmediatamente a convertirse en control omnipotente del encuentro terapéutico. Lo que definió el vínculo con este paciente es convertir en audiencia al terapeuta, observando su despliegue exhibicionista narcisista, ignorando las intervenciones del terapeuta o al menos tratando de impedirlas. En otros momentos la devaluación crónica del terapeuta o el sentimiento de combatirlo para no sentirse dañado. Todos estos aspectos fueron señalados paciente y sistemáticamente en los primeros meses de los tres años que se ha prolongado hasta ahora la terapia.

Este es el desafío terapéutico poder acometer las defensas del paciente, contener sus afectos y aquellos estados que el paciente no puede asumir, sin caer en la tentación de actuar aquello que desplaza en nosotros como terapeutas.

Vemos cómo el paciente, al comienzo de la terapia, no podía mentalizar su sí mismo grandioso porque no existía la posibilidad de distancia necesaria para poder pensarse a sí mismo, puesto que el sí mismo en él era lo mismo que su ser grandioso y omnipotente perfecto. Un sí mismo grandioso con aspectos sádicos. En principio el paciente no pudo aceptar ninguna falla en sí mismo pensando que el terapeuta tampoco aceptaría las suyas. Es un reto para nosotros, como terapeutas, asumir la incapacidad que el paciente nos atribuye, la supuesta incompetencia del terapeuta que el paciente persigue y todo ello sin caer en el desastre o en el infierno más absoluto que, en definitiva, es lo que más teme el sujeto narcisista. Aceptar los fallos que el paciente desplaza en el terapeuta es una sorpresa para el paciente incluso podemos decir que fue una experiencia correctiva en el encuentro con este paciente.

Después de este primer periodo pasamos a otro periodo diferente que coincide con la muerte de su primo por cáncer. Aparece la motivación real de su asistencia "no quiero perder a mi novia", "tengo miedo a padecer cáncer", "antes vine porque ella me envió a terapia", hay un tono en su voz, sus palabras, sus gestos, en su lenguaje no verbal más egodistónico, más implicado. 
En este otro periodo o momento la transferencia narcisista "tu no vales" y paranoide "se va a reír de mí", se va transformando en una transferencia vincular más amigable-ideal. Es una transferencia menos tormentosa, más calmada. La capacidad para mentalizar es más evidente "yo sé que no es fácil estar conmigo me siento desvalorizado y mi primer impulso es ponerme por encima...quizás me siento inferior, me pongo por encima y eso me calma". Surge más capacidad para comprender su miedo a ser sometido que estaba totalmente escindido de su parte grandiosa y de control. Se hace más consciente de la envidia hacia los demás, las mujeres que pueden someterlo con sus encantos.

Otra cuestión que nos parece importante trabajando con organizaciones confusionales de la personalidad, o esquizoides, es discriminar en qué fase o momento estamos con el paciente y cómo podemos diferenciar el paso de un momento a otro, es decir el paso de una fase inicial del tratamiento a una fase media y una fase final. Entendemos que las fases no son estrictamente delimitadas, pero podemos considerar que la fase o momento medio está presente cuando hay mayor capacidad de mentalización y reflexión en el paciente, cuando progresivamente va surgiendo un yo observador que genera el espacio suficiente para poder pensarse a sí mismo. Por ejemplo, el paciente comienza a traer a terapia material de sesiones anteriores asociándolo con aquello que le ocurre. También en esta fase los afectos son más regulados y más calmados, con menor reactividad, más alejados de las etapas tan idealizantes y persecutorias del comienzo, aunque por momentos pueden surgir reacciones terapéuticas negativas ante los avances.

En esta segunda etapa de la terapia nuestro paciente pudo reflexionar sobre sus vínculos familiares, sobre la feroz envidia hacia su hermana, sobre las luchas de poder con su madre y la identificación con una madre conflictiva y dominante. También su necesidad de sentir la superioridad con un padre devaluado e impotente frente a su madre. Es decir, el paciente puede pensarse identificándose con un ser superior, dominante y grandioso como su propio tío (en realidad el ideal materno) o con un ser impotente frente a las mujeres (el padre devaluado). Y la solución que el paciente elige, al verse frágil y pequeño, es buscar la fuerza fuera, el poder fuera, ya sean mujeres ideales o terapeutas-padres perfectos, pero desde el momento que hace esta elección es una ofensa a su propia estima. Este es el drama de Pierre, un drama vital que necesitamos sostener para que tenga el valor de comprender, junto al terapeuta, otras posibilidades vitales sin el desastre que él presiente.

Podemos pensar también un tercer momento terapéutico que aún está por transitar. Este otro momento exige verdaderas renuncias, muy dolorosas en realidad. Nos referimos al duelo por el ideal que nunca estará, que no está en la realidad y es fuente de eterno sufrimiento y frustración. La renuncia a la idea de la mujer perfecta y al padre terapeuta ideal 
en el vínculo terapéutico. Acompañar este proceso supone un sutil reconocimiento del sufrimiento del paciente, la valoración de su esfuerzo y valentía y el cuidado y la paciencia para no dañarlo en este momento tan sensible.

Es un camino de ida y vuelta. Por un lado, poder soltar, pero soltar es caer en los infiernos para este paciente. Pero por otro poder soltar y confiar en que lo que hay abajo no es soledad total ni desamparo total, que el terapeuta y el mundo seguirán ahí. Y por otro, seguirá ahí un terapeuta imperfecto, una persona normal con sus fallas y limitaciones, pero seguirá ahí. Este es otro reto, poder ser tolerados por el paciente como alguien que falla, con imperfecciones, es requisito necesario para que el paciente pueda dolerse de la pérdida siempre dolorosa del mundo ideal perdido, del mundo de sus sueños.

La desregulación del narcisismo se produce cuando han sido ignoradas las necesidades del niño, lo que provoca graves alteraciones en la autoestima o la creación de un escudo defensivo grandioso (Morrison, 2008). Las expresiones del narcisismo herido quedan guardadas en el interior. Las heridas y detenciones en el desarrollo pueden ser provocadas también por demandas excesivas. Subraya la relación íntima que guardan el narcisismo y el sentimiento de vergüenza, relación a la que el autor ha denominado "dialéctica del narcisismo" (The Dialectic of Narcissism). En Pierre identificamos desde diferentes ángulos esas carencias, con una madre poco afectiva que se ocupa formalmente de él y un padre distante y poco cuidador.

Como ocurre habitualmente en la clínica, la persona no encaja de manera monolítica en ninguno de los prototipos recogidos en la literatura. Aquellos sujetos, que ni siquiera llegan a ser pacientes porque no siente que nada vaya mal en su funcionamiento, que asumen de manera más completa la personalidad narcisista pura (de "piel dura" los llamamos), en caso de acudir a terapia no evolucionan de manera positiva, no alcanzan, formas maduras de gratitud y preocupación por el otro (reparación) ni rudimentos de culpa. En ocasiones hemos atendido a narcisistas con un sentimiento de rencor importante que buscaban al terapeuta como objeto de venganza, acumulando tras los años multitud de terapias fracasadas, siempre justificadas en la impericia del terapeuta o en sus supuestas deficiencias de carácter o de ética. En otras ocasiones lo que se busca es un justificante médico o legal para una baja laboral o informe para uso en el ámbito judicial. Los pocos sujetos narcisistas que solicitan atención psicológica es por haber sufrido un fracaso relacionado con situaciones de examen, en unas oposiciones, por ejemplo, también un fracaso amoroso. Pero, una vez recompuestas las defensas, y a no existe mayor motivo de indagación.

En el narcisista próximo a la organización límite - Kernberg diría "límite alta", nosotros preferimos decir "de posición confusa" -, donde podríamos situar a Pierre, se descubre la 
capacidad, en ocasiones, de evolucionar en una línea favorable, aunque muchas veces se vea obligado a suplir la carencia de empatía originaria mediante una reconstrucción intelectual de las situaciones relacionales, sobre cómo se siente el otro (mentalización) y sobre la manera adecuada de responder a dichos sentimientos.

\section{REFERENCIAS}

Bromberg, P.M. (2011). The shadow of the tsunami: and the growth of the relational mind. New York: Routledge.

Coderch, J. (2006). Pluralidad y Diálogo en Psicoanálisis. Barcelona: Herder.

Erikson, E.H. (1959). Identity and the Life Cycle. Psychological Issues, I,1, monograph 1.

Fairbairn, W.R.D. (1940). Factores esquizoides de la personalidad. En Estudio Psicoanalítico de la Personalidad. Buenos Aires: Hormé, 1978.

Fonagy, P. (1991). Thinking about Thinking: Some Clinical and Theoretical Considerations in the Treatment of a Borderline Patient. International Journal of Psychoanalysis, 72, 639-656.

Freud, S. (1925). La Negación. En Obras Completas (vol. III). Madrid: Biblioteca Nueva, 1973.

Freud, S. (1927 e). El Fetichismo. En Obras Completas (vol. III). Madrid: Biblioteca Nueva, 1973. Fetischismus. En Studienausgabe (vol. III). Frankfurt am Main : S.Fisher, 1975.

Kernberg, O. (1992). La agresión en las perversiones y en los desórdenes de la personalidad. Buenos Aires: Paidós, 1994.

Kernberg, O. (1996). A Psychoanalitic Theory of Personality Disorders. En J.F. Clarkin y M.F, Lenzenweger (comps.). Major Theories of Personality Disorders. Nueva York: Guilford.

Kohut, H. (1966). Forms and Transformations of Narcissism. Journal of the American Psychoanalytical Association, 14, 243-272.

Kohut, H. (1971). Análisis del Self. Buenos Aires: Amorrortu.

Mitchell, S. (1988). Relational Concepts in Psychoanalysis: An Integration. Cambridge (MA): Harvard University Press.

Morrison, A.P. (2008). Fenómenos Narcisistas y Vergüenza. Clínica e Investigación Relacional, 2, $1,9-25$.

Rodríguez Sutil, C. (2014). Psicopatología Psicoanalítica Relacional. Madrid: Ágora Relacional.

Rosenfeld, H. (1987). Impasse e Interpretación. Madrid: Tecni-publicaciones, 1990.

Zukerfeld, R. y Zonis, R. (2011). Vicisitudes traumáticas, vincularidad y desarrollos resilientes: Un modelo de investigación dimensional. Clínica e Investigación Relacional, 5, 2, 349-369.

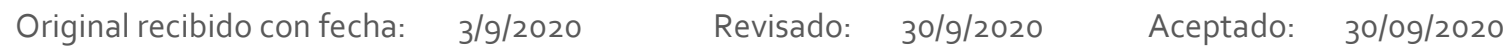

